\title{
The use of digital technologies in the process of organizing volunteer activities of preschoolers
}

\author{
Marina Zelenskaya ${ }^{1,{ }^{*}}$, Nina Tatarintseva ${ }^{1}$, and Natalia Berdnikova ${ }^{2}$ \\ ${ }^{1}$ South Federal University, 105/42 Bolshaya Sadovaya Str., 344006 Rostov-on-Don, Russia \\ ${ }^{2}$ Municipal budgetary preschool educational institution No. 50, Rostov-on-Don, 38, Petrovskaya Str., \\ 344022 Rostov-on-Don, Russia
}

\begin{abstract}
Recently, digital technologies have more and more come into our lives (distance learning, developing Internet platforms, digital teaching aids, etc.). It is not surprising that at the stage of preschool childhood education has undergone significant changes. Digital technologies today are a new way of transferring knowledge, a means of improving the efficiency of the educational process. The article presents the experience of involving older preschoolers in volunteer practices in order to develop initiative, socialization based on the use of digital technologies.
\end{abstract}

\section{Introduction}

Modern society is a dynamic system and constantly evolving system, it sets itself more and more complex tasks. To achieve them, various digital technologies are being created and improved, which are an integral part of our life.

It's hard to imagine what would happen if people gave up interacting with digital technologies even for one day. Today information technologies endow us with a wide range of opportunities (exchange of accumulated experience and knowledge; communication of people regardless of their location; implementation of complex and voluminous mathematical calculations; the emergence of distance learning and much more).

It should be noted that a person's familiarization with the benefits of the digital world begins from a childhood. Every day the child sees how parents or other people use digital tools. The baby from the cradle got used to their constant presence. From early childhood, children become active consumers of digital technologies (they watch their favorite cartoons, children's programs, play educational games, get acquainted with interest with mobile phones, tablets, game consoles, etc.). And by the age of 6-7 they become part of the modern information society. It is obvious that in the last decade of the 21 st century, the socialization of the child is under the influence of the digital environment.

In the works of B.D. Parygina, A.I. Kovaleva, G.M. Andreeva emphasizes that the integration of a child into society, his mastering of social values, norms and rules of behavior implies the active activity of the individual himself to transform the surrounding society.

B.D. Parygin emphasizes that "while experiencing the influence of the environment, social institutions and his own activities, a person is, at the same time, relatively autonomous

\footnotetext{
${ }^{*}$ Corresponding author: m.zelinsckaia@yandex.ru
} 
in the development of his inner world, in the development of self-awareness and self-attitude. The active life position of the individual lies precisely in his ability to carry out the functions of self-control, self-regulation, self-affirmation and self-awareness" [1].

The question arises: "What kind of factors influence the process of socialization of a preschooler?" We have found the answer in the works of A.V. Mudrik. The scientist writes that the process of socialization of preschool children is influenced by a group of factors: mega-factors (space, Internet, etc.), macro-factors (society, state, etc.), meso-factors (city, district, etc.), micro-factors (family, kindergarten, peers, etc.) [2].

In connection with the above, one of the important tasks of socialization is the formation of a socially active personality, capable of creative activity, self-realization, which has established a harmonious system of relations to other people, society, work, and to oneself.

L.S. Vygotsky [3] in his scientific works emphasized that the successful development of a child's personality is possible in an active variety of activities. The well-known psychologist conditionally divided the types of activity into a "zone of actual development" (a set of knowledge, skills and abilities that a child possesses at a high level at a given time) and a "zone of proximal development" (a level of development that a child achieves in the process of communicating with an adult, not by imitating the action of an adult, but by solving problems that are in the zone of his intellectual capabilities). In our study, we consider volunteering as a factor in the socialization of preschool children.

In recent decades, a fairly wide interest of specialists in various fields of activity is directed to volunteering: $\mathrm{H}$. Clark studied the relationship between volunteerism and social exclusion [4], J. Dean devoted his article to informal volunteerism [5], S. J. Ellis described the specifics of organizing volunteer activities in the United States [6], A. Galea conducted a study of the phenomenon of volunteerism in England [7], A. Gil-Lacruz in his works presented a comparative analysis of volunteerism in Europe [8], C. Holdsworth, L. Salamon, F. Wardell, J. Lishman has developed the «case study» of volunteerism for students of higher educational institutions $[9 ; 10]$, A. Jones in his article describes the theoretical aspects of international youth volunteerism [11], E. Kiptot, S. Franzel in their research talk about volunteerism as an investment in human, social and financial capital [12], S. K. Nenga studied the phenomenon of volunteerism among different segments of the population [13], T. Rotolo described the features of volunteerism of American women [14], M. V. Pevnaya devoted her works to youth volunteerism movement in Poland [15].

R. A Cnaan, L. Amrofell [4] hold that "volunteerism" is one of the forms of freely implemented social behavior that is for the benefit of society, as well as the volunteer himself, and which is not motivated by financial considerations.

Y.J. Lee, J.L. Brudney [17] subdivides volunteering into "formal" and "informal". From the point of view of scientists, formal volunteer activities can be carried out in any non-profit organization, and informal volunteering activities - exterior to formal organizational structures (includes assistance provided to friends, family members, is carried out outside the organizational context).

E.A. Shutikova, in her research, distinguishes three types of volunteering organizations: associations of volunteers based on charitable foundations, communities formed by the volunteers themselves, and the formation of a favorable environment for training, education and support of volunteers [18].

In our study, we focus on the informal type of volunteering as an age-appropriate form of volunteering for preschool children. We take as a basis the definition of volunteerism, formulated by J. Wilson, according to the scientist, "this is an activity for the benefit of another person, group or organization." The volunteer movement serves as an excellent training for successful adaptation and provides an opportunity for personal self-realization [19]. 
The content of the components of socialization was determined by us taking into account the age characteristics of preschool children. In her article, T.M. Churekova writes that for older preschool children, play and communication are the leading activity. In the process of communication, the child actively learns the world around him, and interested in the "world of people" [20].

The participation of children in volunteer activities satisfies this need for communication, contributes to the successful socialization of children, creates conditions for the development of socially significant personal qualities, the manifestation of initiative.

Today, when information acts as a strategic resource for the development of society, it becomes obvious that the use of digital technologies in various fields of activity is inevitable, and as the situation during the COVID-2019 pandemic has shown is vital.

The rapidly developing process of digitalization of education was also supported at the government level. In the Decree of the President of the Russian Federation V.V. Putin "On national goals and strategic objectives of the development of the Russian Federation for the period up to 2024" made an emphasis on the creation of a modern and safe digital educational environment that ensures high quality and accessibility of education of all types and levels ", and also emphasizes the need for the introduction of digital technologies and platform solutions in the education sector.

In modern science, there are various approaches to the interpretation of the concept of "digital technologies". For example, R.V. Ershova, N.N. Kiseleva, N.N. Saveliev write that digital technologies should be considered as a method of encoding and transferring information, which allows you to instantly perform a variety of diverse tasks. When choosing a particular technology, the teacher must rely on the child's "knowledge base" (the level of development of mental processes, cognitive abilities, value-semantic sphere); the level of professional competence in the field of information technology; design of digital tools, their accessibility, and the content presented in them [21].

A. Marey considers digitalization "as a change in the paradigm of communication and interaction with each other and society [22].

M.N. Erokhin, Yu.S. Tsench [23] write that digital technologies are being developed for a high-speed, effective, attractive presentation of information in teaching and upbringing, for creating interesting modern teaching materials, in order to increase teaching efficiency and build a new fascinating educational and educational environment: developing and technological. These include e-learning systems (Google Classroom, Yandex.Tutorial, Stepik, Canvas), video services (YouTube), services for working with graphics (Pictochart, Canva), game educational materials (LearningApps).

In our study, we adhere to the point of view that digital technologies are electronic tools, systems, devices and resources that generate, store or process data and allow an attractive presentation of information, expand additional opportunities, and make changes in the educational environment. Modern digital technologies used in preschool education include: "educational robotics", "interactive electronic content", "virtual reality" technology, "multistudio", etc.

E.O. Smirnova, N.Yu. Matushkina, S.Yu. Smirnova [24] studied the influence of virtual reality on the development of children of early and preschool age and noted that the place of digital technologies in education, their comprehensive application has become the subject of study by scientists from various fields of knowledge. Teachers note the importance of the practical traditional activities of children and the prevention of belittling the role of the teacher, as well as replacing traditional developmental technologies with digital ones.

Indeed, in older preschool age, children continue to form cognitive and volitional prerequisites for the successful mastering of various types of activity, and personality socialization takes place. It is during this period that it is important for a preschooler to 
support adults in the manifestation of children's initiative and independence, as well as in mastering digital technologies.

In the works of G.U. Soldatova, O.I. Teslavskaya presents evidence proving the social significance and merits of using digital gaming technologies. According to the authors, these technologies help to increase the child's confidence in their abilities, develop attention, memory, thinking, communication of children with peers and adults [25].

T.A. Abramovskikh [26] directs teachers to be guided by pedagogical expediency while using digital tools in their work with preschoolers (for example, when comparing the effectiveness of digital and traditional technologies, to leave an advantage to the latter).

The use of digital technologies in the volunteer activities of older preschoolers is due to the requirements of conceptual regulatory documents in the field of education, the needs and age characteristics of older preschool age, and research in the field of digitalization and volunteering.

The purpose of our study is to prove the effectiveness of using digital technologies in the process of organizing volunteer activities for older preschool children.

\section{Results of the research.}

"Voluntary activity of preschool children" is understood as a voluntary, socially useful, gratuitous initiative aimed at helping others, in a social, cultural, environmental, sports orientation, performed in a joint organized (unorganized) form with adults, in the form of single short-term actions ( regular systematic activity), which is of a subjective nature (volunteering as "co-existence", "leisure volunteering", family volunteering, online volunteering, etc.).

In the study, the author's program "Young Volunteers" was developed. The program has a pronounced social and pedagogical orientation, its content contributes to the development of creative, intellectual, research initiative, digital socialization in preschoolers. The implementation of this program meets the requirements of modern socio-cultural conditions for the development and education of older preschool children.

The program includes the following interrelated sections "Journey into the past of the volunteer movement", "Social volunteering", "Cultural volunteering", "Environmental volunteering", "Sports volunteering".

To implement the "Young Volunteer" program in a preschool educational organization, certain conditions must be created that meet the requirements of the Preschool Education Standard

Table 1. Conditions for the implementation of the "Young Volunteer" program.

\begin{tabular}{|l|l|}
\hline Conditions & Content \\
\hline material-and- & $\begin{array}{l}\text { computer, tablets, multimedia installation, Internet connection, the } \\
\text { availability of the necessary equipment for holding social events (for } \\
\text { example, visual materials for making crafts, children's literature, a } \\
\text { volunteer uniform, etc.); cultural (for example, theatrical attributes: } \\
\text { masks, costumes, etc.); sports (for example, physical education } \\
\text { equipment, children's exercise equipment, etc.), environmental (for } \\
\text { example, equipment for working in the garden, vegetable garden, etc.); }\end{array}$ \\
\hline $\begin{array}{l}\text { psychological } \\
\text { and pedagogical }\end{array}$ & $\begin{array}{l}\text { respect for the personality of the child, children's subculture, children's } \\
\text { activities, support for independence, initiative, positive self-esteem, } \\
\text { the use of methods, techniques and forms in working with children that } \\
\text { are adequate to age, individual, psychological and pedagogical } \\
\text { characteristics; }\end{array}$ \\
\hline
\end{tabular}




\begin{tabular}{l|l}
\hline $\begin{array}{l}\text { developing } \\
\text { object-spatial } \\
\text { environment }\end{array}$ & $\begin{array}{l}\text { equipment in the group room of the volunteer activity corner, which } \\
\text { includes: volunteer uniforms (T-shirts, caps with the "I am a } \\
\text { volunteer" emblem); a mailbox containing requests for help; albums, } \\
\text { illustrations, photographs illustrating the history of the development of } \\
\text { volunteering in Russia and abroad, children's literature telling about } \\
\text { various types of assistance to children, adults, animals; flow charts for } \\
\text { the manufacture of handicrafts from paper and waste material; Kids } \\
\text { toys; boxes with attributes for social, cultural, sports, environmental } \\
\text { actions. }\end{array}$
\end{tabular}

The main directions of volunteer activities of preschoolers, within the framework of the program developed by us, are:

- social events (flash mobs of a social orientation, for example, \# we are together, \# thanks to doctors, etc., helping the kids, helping the janitor, events to promote safe life: "close the windows", "be careful on the pond", etc.)

- environmental campaigns (collection of waste paper and plastic lids, planting trees and participating in voluntary clean-ups, handicrafts from waste material as popularization of ecological culture and respect for the world around them, bird feeders, etc.)

- health-preserving actions (for example, "Support the football team", "I choose sport", etc.)

The motivational basis for the participation of preschool children in volunteer activities is the need for a sense of community and communication. Awareness of their opportunities in society, understanding the role of their personal contribution to the arrangement of the house, kindergarten, group helps a growing person to successfully socialize, because he finds himself in a situation where it is important to show the personal qualities of a mature person, such as care, compassion, charity, initiative.

Volunteering is a way to meet social and psychological goals. In addition, it is important to emphasize that people can have a wide range of motivations for volunteering [17].

Responding to the challenges of today, kindergartens strive to develop such educational approaches to the development of the preschool child's personality that are able to integrate the child into the dynamic high-tech world of knowledge and information.

In our study, we developed a step-by-step mechanism for applying digital technologies in the process of organizing volunteer activities of preschoolers.

The first stage is pre-informational: children are introduced to the ideas of volunteering on the example of cartoon characters or fairy tales; It is possible to show presentations, videos about volunteering with Internet resources Unified information system "Volunteers of Russia" (thanks to the ease of use and convenient interface of this platform, children together with adults find up-to-date information about volunteer activities in the city, which allows children to feel involved in adult real life and entering the social community).

The second stage is a problem-search: detection of a social problem (it is carried out by receiving an unexpected letter to the teacher's email with a request for help or a description of the problem situation, this can be an interactive video with an appeal to children or an appeal to participate in the action). There are several ways to detect problem situations: one of them is when there is a clear formation and description of the problem in an accessible language for older preschool children using multimedia devices to visualize the topic. Children in this situation express their subjective position through the choice of activities, expressing a desire to participate in volunteer activities. For example, a video message from a sports team calling for participation in a flashmob, or an unexpected demonstration on an interactive whiteboard of an announcement about collecting waste paper or planting trees. The second way is when there is no direct indication of the problem. Children need to see the difficulty, "open" the problem. For this purpose, a "social history" or the creation of an environment aimed at detecting the problem that needs to be solved will be suitable. For 
example, the presentation that some urban birds do not fly to south and it is difficult for them to find food under the snow in winter. Or a container for collecting plastic bottle caps appears in the group as providing a choice of environmental disposal after their use, also it is possible to use some digital tools during the presentation (interactive whiteboard, laptop tablet) about environmental topic in the context of the created "challenge environment". In this case, children show curiosity, ask questions "what?", "why?", "what to do?", kids express concern or feelings about the situation, analyze whether such problems have occurred in the experience of the older preschooler or his environment, rely on the initial experience of the child and the awareness of the problem situation.

The third stage is organizational: after the over-fives preschoolers have become familiar with the concept, idea and traditions of volunteerism, after the problem is posed, the planning of volunteer projects takes place. And here it is also possible to use digital tools: interactive whiteboards drawing up a project plan, etc. Children express their suggestion to solve problems, look for ways to implement them, set tasks with the help of a teacher and plan the sequence of implementation. First, they draw on stickers their ideas, then teacher collect, organize and demonstrate them through digital tools, thus teacher together with the children, can track the completion of their tasks. This can also be done with the help of an interactive character through the "wanderer/exploration game" from task to task, from stage to stage, which were determined by preschoolers.

The fourth stage is the final one and most emotional. The following types of volunteer activities that can be implemented in the conditions of a preschool educational organization with the involvement of social partners and parents are appropriate and accessible for older preschool children:

- social volunteering - voluntary activities aimed at helping the social environment: younger preschoolers, children who need special attention, elderly people, veterans, people with disabilities (for example, children accompanied by adults create video cards, shoot thematic videos, play with kids in interactive toys, etc.);

- environmental volunteering - voluntary activities aimed at caring for the surrounding world include garbage collection, tree planting, education of citizens in the field of environmental protection, etc.: the actions are covered through publications in social networks about children's and adult environmental activities and as a demonstration of children's results in this activity (for example, the "Eco-style" campaign, in which children and their parents made outfits from environmental waste materials, or an announcement about the collection of waste paper or social and environmental campaign for gathering plastic bottle caps, as well as viewing educational cartoons, such as the series "Committee for the Protection of Copyright of Nature", etc.).

Event volunteering - volunteer initiatives aimed at participating in events or helping to organize them. Thus, children of Rostov-on-Don kindergarten № 50 participated in the interactive action \#ThanksDoctors as a sign of gratitude to the doctors for their work during the COVID-2019 pandemic, children of Rostov-on-Don kindergarten № 77 used social networks to kindly appeal to pensioners to stay at home during the most difficult days of the pandemic and through the «All-Russia People's Front» (a social movement created in May 2011 at the initiative of Russian President Vladimir Putin, which unites active and caring residents of the country) gave their drawings to the elderly people. Also, during the period of isolation, children together with their parents organized a flashmob of their favorite teachers in social networks, filmed a video message with words of love and hope for a meeting in the walls of their favorite kindergarten.

When creating and implementing volunteer projects, we used materials for conducting additional classes with children, for example, videos on charity topics from the educational online platform "School of Positive Habits" (https://positiveschl.ru/). The classes were organized in such a way as to create a space for active dialogue, and communication was as 
productive as possible. This is facilitated by animated films created for each topic. Their style is based on children's graphics, the plot of the cartoon leaves a problematic question at the end, which gives "mental food", material for discussion, and an impulse for initiative.

\section{Conclusion}

Consequently, our research proved the effectiveness of the use of digital technologies in the process of organizing volunteer activities of older preschool children. The participation of older preschool children in volunteer activities shows that preschoolers involved in volunteer projects actively develop initiative, develop team experience, acquire the skill of planning and designing activities, have the opportunity for self-realization and expand the communicative circle and enrich knowledge about social and environmental volunteer activities.

The inclusion of the digital environment in educational work allows you to activate preschoolers and involve them in various socially-oriented projects, to do all possible good deeds. The use of digital tools and educational materials posted on special online platforms allows you to create an additional environment for the formation of social responsibility, the development of initiative and socialization of preschoolers.

The reported study was funded by RFBR, project number № 19-313-90065 от 02.09.2019 г.

\section{References}

1. B.D. Parygin, Social psychology Origins and prospects, 533 (Saint-Petersburg SPBGUP, 2010)

2. A.V. Mudrik, Socialization - the field of systemic changes, Issues of education 4, 114 (2014)

3. V.V. Davydov, Vygotsky Pedagogical Psychology, 671 (Moscow, AST-Astrel, Guardian, 2008)

4. H. Clark, Volunteering for All? Exploring the link between volunteering and social exclusion, 66 (UNV, 2012)

5. J. Dean, Challenging narratives: the importance of informal volunteering, Research archive SHU. NCVO/VSSN Researching the Voluntary Sector Conference, NCVO, London, 7-8 September 201 (2011)

6. S.J. Ellis, Volunteering: an american tradition, The Spirit of Volunteerism. Wash., DC 20522-0501 (2012)

7. A. Galea, Volunteering in acute trusts in England Understanding the scale and impact, The British associations of social workers: official website (England: The Kings Fund, 2013)

8. A. Gil-Lacruz, Voluntary Work in Europe: Comparative Analysis Among Countries and Welfare Systems, Springer Science and Business Media B. V., 382 (2012)

9. C. Holdsworth, Volunteering, choice and control: a case study of higher education student volunteering, J. of Youth Studies 17(2), 204-219 (2013)

10. L. Salomon, Measuring the economic value of volunteer work globally: concepts, Estimates and a roadmap to the future, Annals of Public and Cooperative Economics. USA. 82(3), 217-252 (2011)

11. A. Jones, Theorizing international youth volunteering: training for global (Corporate) Work? Transactions of the Institute of British Geographers 36(4), 530-544 (2011) 
12. E. Kiptot, Voluntarism as an investment in human, social and financial capital: Evidence from a farmer-to-farmer extension program in Kenya, Agriculture and Human Values 31(2), 231-243 (2014)

13. S. K. Nenga, Volunteering to give up privilege? How affluent youth volunteers respond to class privilege, J. of contemporary ethnography 40(3), 263-289 (2011)

14. T. Rotolo, State-level differences in volunteerism in the united states:research based on demographic, institutional, and cultural macrolevel theories, Nonprofit and Voluntary Sector Quarterly 41(3), 452-473 (2011)

15. M. V. Pevnaya, Youth volunteering: the way to the regional labor market or source of human resources loss, The Conference Proceedings The 8th International Days of Statistics and Economics, 1145-1153 (Prague, 2014)

16. R.A. Cnaan, L. Amrofell, Mapping Volunteer Activity. Nonprofit and Voluntary Sector Quarterly 23(4), 335-351 (1994) doi:10.1177/089976409402300404

17. Y. J Lee, J.L Brudney, Participation in formal and informal volunteering: Implications for volunteer recruitment. Nonprofit Management and Leadership 23(2), 159-180 (2012)

18. E.A. Shutikova, Organizational foundations of volunteering in the Russian Federation. In Good governance as a factor of sustainable development of the territory, 119-124 (2018)

19. J. Wilson, Volunteering. Annual review of sociology 26(1), 215-240 (2000)

20. T. M. Churekova, Socialization of preschool children as a socio-pedagogical problem. Bulletin of the Kemerovo State University. Series: Humanities and Social Sciences 1(1) (2017)

21. R.V. Ershova, N.N. Kiseleva, S.V. Saveliev, Digital society as a cultural and historical context of human development (2018)

22. A. Marey, Digitalization as a Paradigm Change (2019)

23. M.N. Erokhin, Yu.S. Tsench, Formation of an integrated digital scientific and educational space in the network interaction of engineering universities and research centers. Bulletin of the Bashkir State Agrarian University 3, 27-30 (2018)

24. E.O. Smirnova., N. Yu. Matushkina, S. Yu. Smirnova, Virtual reality in early and preschool childhood, Psychological Science and Education 23(3), 42-53 (2018) doi: 10.17759 / pse. 2018230304 .

25. G.U. Soldatova, O. I. Teslavskaya, Video games, academic performance and attention: experience and results of foreign empirical studies of children and adolescents, Modern foreign psychology 6(4), 21-28 (2017) doi: 10.17759 / jmfp.2017060402

26. T.A. Abramovskikh, Features of the selection of the content of additional professional programs based on diagnostics of the subjective position of students from among the leaders of educational organizations, Scientific support of the system of staff development, 3(32), 52-63 (2017) 